\title{
A composição dos custos de armação e a renda das expediçóes de pesca da frota pesqueira artesanal da região do Médio rio Madeira, Amazonas, Brasil ${ }^{1}$
}

\author{
Renato Soares CARDOSO², Carlos Edwar de Carvalho FREITAS 3
}

\section{RESUMO}

Estudos buscando identificar as características físicas, operacionais e econômicas da frota pesqueira sediada na Amazônia Central foram efetuados, deixando lacunas sobre as características da frota nas regiōes periféricas. Este trabalho teve como objetivo analisar os custos necessários para a entrada de novas embarcações na atividade pesqueira e fornecer informações relativas ao custo das expedições e da renda econômica da atividade. O estudo foi realizado na regiāo do Médio rio Madeira e foram coletadas por intermédio de questionários, informações sobre os custos de manutenção, armação e a renda das viagens de pesca, no período de junho de 2003 a maio de 2004, junto aos proprietários ou encarregados de barcos de pesca e pescadores de canoas motorizadas. O maior investimento dos proprietários de embarcações foi para a aquisição dos apetrechos, sendo os próprios pescadores os principais financiadores. As expediçōes de pesca das embarcaçōes foram financiadas por seis agentes, sendo os principais financiadores os pescadores e o frigorífico. O combustível foi o principal item dos custos a encarecer as expediçōes dos barcos e, combustível e gelo, como custo encarecedor para as canoas. Os armadores e encarregados de barcos de pesca ganharam em média 0,6 e 0,5 salário mínimo, respectivamente, por expedição, e os pescadores 0,3 salário mínimo, enquanto pescadores de canoas motorizadas ganharam em média 0,5 salário mínimo.

\section{PALAVRAS-CHAVE}

Amazônia, pesca interior, economia pesqueira, custos, rendimento econômico.

\section{The composition of cost and income of fishing expedictions of small-scale fishing fleet in the Medium Madeira River region, state of Amazonas, Brazil}

\begin{abstract}
Studies emphasizing the physical, operational and economics characteristics of the fishing fleet were realized, focusing the fleet based in Central Amazon but with gaps about the characteristics in peripheral regions. In this sense the work aimed to analyze the necessary costs to entry of new vessel on activity and to provide information in relation to the costs of fishing expeditions and economic revenue offishing activity. The study was realized in the Medium Madeira River region and collected information about maintenance, cost and income of fishing expeditions, from June 2003 until May 2004, using questionnaires applied to skippers and fishers of boats and motorized canoes. The gear it was most expensive item on acquisition and the fishers the financer. The fishing expeditions of vessels were financed by six agents, fishers and ice plant owner were the principal financers. Fuel was the main items of cost on fishing expeditions of boats, fuel and ice to motorized canoes. The skippers and owners of fishing boats had a clear gain of 0.6 and 0.5 living wages by fishing expeditions and the fishers 0.3 while fishers of motorized canoes had a clear gain of 0.5 living wages.
\end{abstract}

\section{KEY-WORDS}

Amazonian, inland fisheries, fisheries economy, costs, economic revenue.

\footnotetext{
${ }^{1}$ Parte da Dissertação de Mestrado do primeiro autor do curso de Biologia de Água Doce e Pesca Interior do Instituto Nacional de Pesquisas da Amazônia. ${ }^{2}$ Universidade Federal do Amazonas. Av. Gal. Rodrigo Otávio, 3000. Aleixo. CEP 69077-000. Manaus, Amazonas, Brasil. Tel. (92) 3647 4064. E-mail: rsconpisci@yahoo.com.br ${ }^{3}$ Departamento de Ciências Pesqueiras, Universidade Federal do Amazonas. Av. Gal. Rodrigo Otávio, 3000. Aleixo. CEP 69077-000. Manaus, Amazonas, Brasil. Tel. (92) 3647 4064. E-mail: cefreitas@ufam.edu.br
} 


\section{INTRODUÇÃO}

A frota pesqueira amazônica de água doce é composta de barcos de madeira, equipados com motores de centro e por canoas impulsionadas à vela, a remo ou com motores de popa, conhecidos regionalmente como rabetas (Petrere Jr., 1978; Barthem, 1999; Almeida et al., 2001; Batista et al., 2004). Essa frota explota uma grande quantidade de espécies de peixes e utiliza vários apetrechos de pesca, destacando-se o uso da redinha e da malhadeira pelos pescadores dos barcos e malhadeiras e apetrechos de fisga pelos pescadores das canoas (Petrere Jr., 1978; Isaac \& Barthem, 1995; Batista, 1998; Cardoso et al., 2004).

$\mathrm{Na}$ Amazônia, a atividade pesqueira apresenta fortes variaçōes de intensidade, em função de vantagens e desvantagens sazonais que resultam em elevada mobilidade econômica. Um importante exemplo desta mobilidade são alguns barcos de pesca, principalmente os de pequeno porte, que na entressafra, ou dependendo da situação ou conveniência, podem ser utilizados para o transporte de pessoas e cargas. Esta mobilidade não ocorre, no entanto, para os tripulantes, que apesar de todas as restriçōes impostas, continuam na atividade, trabalhando em outras embarcaçōes de pesca (Almeida et al., 2003).

Para a entrada de embarcaçōes de pesca na atividade, faz-se necessária a aquisição de itens de suporte que são indispensáveis para a prática desta, como canoa, remos, motor rabeta e apetrechos (Faria Júnior, 2002), que são adquiridos de acordo com o tipo de pescaria adotada ou pelas espécies-alvo das mesmas, uma vez que a embarcação não é utilizada efetivamente no esforço de pesca. No entanto, pescadores de canoas isoladas necessitam somente de motor de popa (opcional) e dos apetrechos.

Uma vez iniciada a atividade pesqueira, a permanência insere novos custos sobre o proprietário do bem, como a manutenção do barco, das canoas auxiliares e dos apetrechos de pesca. $\mathrm{Na}$ maioria dos casos, esses custos são arcados pelos donos da embarcação ou compartilhados por todos os tripulantes. Esse fato vem, muitas vezes, onerar ainda mais os custos com as expediçôes, visto que o material utilizado ou a despesa com a mão-de-obra são adicionados aos custos da próxima campanha da embarcação de pesca (Cardoso, 2005).

A atividade pesqueira da região apresenta dois custos que são essenciais para a continuidade: os custos fixos com as taxas (Falabella, 1994; Parente, 1996) e os custos variáveis ou operacionais, decorrentes da armação das embarcaçôes para as expedições de pesca, que dizem respeito basicamente ao combustível, gelo, rancho e adiantamento monetário aos pescadores, além da manutenção dos bens (Falabella, 1994; Parente, 1996; Faria Júnior, 2002; Cardoso et al., 2004).

O caráter estritamente artesanal da atividade pesqueira em águas interiores (Berkes et al., 2001) faz com que a atividade seja classificada em alguns dos seus aspectos de não-eficiente. São citados como exemplos de ineficiência, o sistema de armazenamento do pescado capturado, construído de maneira inadequada, os motores de propulsão que são mais potentes que o necessário para a embarcação, entre outros (Batista \& Petrere Jr., 2003). Esses pontos falhos podem gerar prejuízo pela perda de pescado ou pela não conservação do gelo, ou onerar os custos com as expedições pelo maior consumo de combustível.

Estudos das características físicas, operacionais e econômicas da frota pesqueira sediada na Amazônia Central vêm sendo realizados nas últimas décadas (IPT, 1979; Parente, 1996; Faria Júnior, 2002; Cardoso et al., 2004 e Petrere Jr., 2004). Permanecem ausentes, entretanto, estudos sobre as frotas pesqueiras sediadas em centros urbanos menores, localizados em outros rios da bacia e que são fundamentais para uma análise global da atividade pesqueira amazônica e de sua rentabilidade.

Na tentativa de preencher as lacunas existentes, este trabalho teve como objetivo principal analisar os investimentos necessários para a entrada de novas embarcaçoes na atividade pesqueira em pequenos centros urbanos, bem como fornecer informaçóes relativas ao custo das expedições de pesca e da renda econômica da atividade.

\section{MATERIAIS E MÉTODOS}

\section{ÁREA DE ESTUDO}

O estudo foi realizado na região do Médio rio Madeira, o segundo afluente do rio Amazonas em volume de água (Gibbs, 1969 apud Goulding, 1979), tendo como área focal o município de Manicoré, localizado na porção sudeste do estado do Amazonas (Fig. 1). Os principais locais de pesca desta região abrangem a calha principal do rio Madeira, a foz de cinco rios tributários: Marmelos, Manicoré, Atininga, Mataurá e Mariepaua, além de lagos e outros ambientes sazonais (Cardoso, 2005).

\section{COLETA DE INFORMAÇÕES}

As informaçōes sobre os investimentos iniciais, custos de armação, manutenção dos apetrechos e das embarcaçōes de pesca foram coletadas por intermédio da aplicação de questionários estruturados no período de junho de 2003 a maio de 2004, junto aos proprietários ou encarregados de barcos de pesca e para os pescadores de canoas motorizadas, após a comercialização de pescado no porto de desembarque do mercado municipal.

\section{ANÁLISE DOS DADOS}

Os dados foram armazenados em planilhas eletrônicas e analisados utilizando-se de estatística descritiva (Beiguelman, 2002), para aquisição de média e desvio padrão $( \pm)$. Os valores relativos aos investimentos para aquisição dos apetrechos de pesca equivalem aos valores médios do número presente nas embarcações, bem como os custos de manutenção das canoas e apetrechos, dizem respeito ao número total destes componentes.

A composição dos custos computados para a atividade pesqueira incluiu os dispêndios com os insumos necessários a operação de pesca, em especial, os apetrechos de pesca; os custos 


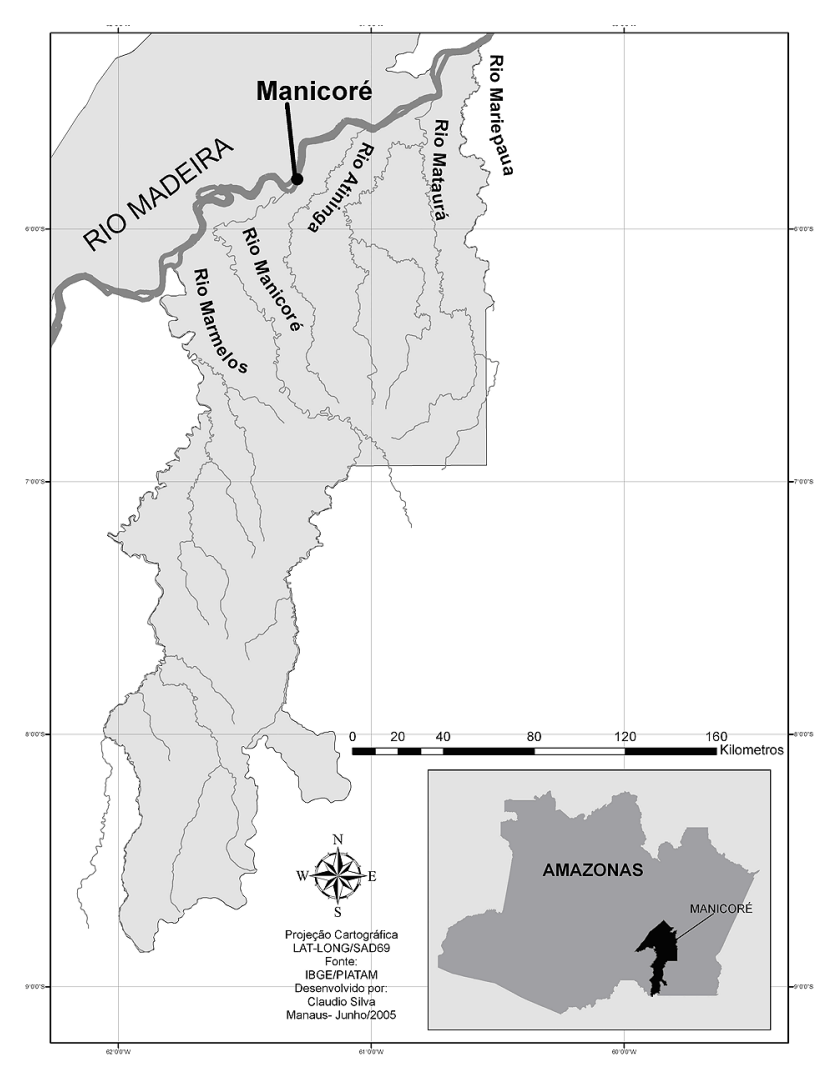

Figura 1 - Município de Manicoré, com a indicação do Rio Madeira e de seus principais afluentes na área em que 0 estudo foi realizado.

com manutenção das embarcaçōes, discriminando os dispêndios com o motor de propulsão e o casco, pintura e calafeto; os custos com o processo de comercialização e, por fim, os custos com as expediçōes de pesca, discriminando a participação relativa dos três itens mais importantes: combustível (diesel, gasolina e óleo lubrificante), gelo para conservação do pescado e o rancho.

As canoas motorizadas, que possuíam apenas a redinha como apetrecho de pesca (duas canoas), foram excluídas do cálculo das canoas, porque o custo de aquisição deste apetrecho é muito alto em comparação ao das malhadeiras e a média deste grupo alteraria a média geral dos custos, o que geraria um valor irreal para a armação de uma canoa.

Para a aquisição do valor da renda líquida da atividade pesqueira das embarcações, foram subtraídos os custos da expedição de pesca dos barcos e canoas motorizadas, da respectiva renda gerada com a comercialização do pescado capturado. Todas as análises foram efetuadas em Real ( $\mathrm{R} \$)$, tomando-se para efeito comparativo o valor do Dólar americano, cotado, em média, a $\mathrm{R} \$ 2,50$ no período do estudo.

\section{RESULTADOS}

\section{ASPECTOS GERAIS DA PESCA LOCAL}

A frota pesqueira do município era formada por quinze barcos de pesca e por aproximadamente 150 canoas, motorizadas e a remo (Cardoso, 2005). Foram aplicados doze questionários para os barcos de pesca, equivalente a $75 \%$ da frota de barcos e 42 questionários para canoas, o equivalente a $30 \%$ das canoas atuantes nas pescarias da região. $\mathrm{O}$ apetrecho predominante nos barcos foi a redinha ou rede-de-lance, seguida por malhadeira, espinhel e grozeira. Quanto às canoas motorizadas, o principal apetrecho foi a malhadeira, embora existissem na época duas canoas que usavam exclusivamente a redinha.

A cadeia de comercialização do pescado local é composta pelos pescadores, que podem ser moradores da zona urbana ou rural, marreteiros, que compram o pescado do pescador e efetuam a revenda (para donos de banca ou vendedores de rua) e pelos vendedores de pescado, que efetuam a venda no mercado municipal ou na rua, em bicicletas adaptadas para o transporte de caixas isotérmicas com pescado refrigerado.

Existe um acordo informal entre os pescadores e os vendedores, que impóe normas ao preço final de comercialização do pescado por vendedores. Enquanto o preço da primeira comercialização é negociado livremente entre o pescador e o marreteiro e/ou vendedor, o valor estipulado para a venda desse mesmo pescado ao consumidor só pode ser acrescido de $\mathrm{R} \$ 0,50$ o kg.

\section{INVESTIMENTOS}

Nos barcos de pesca, excluindo os investimentos dos proprietários com a aquisição do motor de propulsão, casco e casaria, a aquisição dos apetrechos de pesca absorve a maior parte dos investimentos, alcançando cerca de $67,8 \%$ dos investimentos. Os proprietários de canoas apresentaram maiores investimentos com a aquisição das canoas auxiliares e dos apetrechos (Fig. 2).

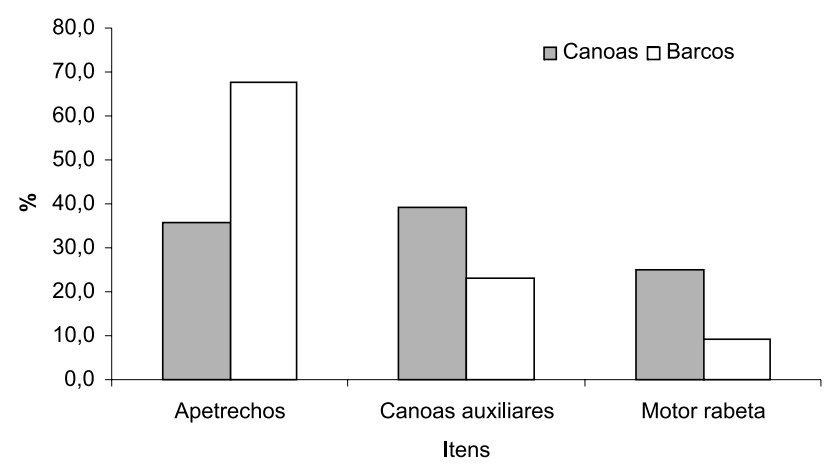

Figura 2 - Percentual de participação nos investimentos dos principais insumos da atividade pesqueira. 
Quanto ao investimento com as canoas auxiliares destaca-se o maior custo das canoas dos barcos de pesca, com custo equivalente ao triplo das canoas dos pescadores de rabeta (Tabela 1). Foi identificado também que a soma dos investimentos e dos custos de manutenção dos barcos de pesca, podem alcançar o triplo dos dispêndios necessários para as canoas motorizadas. $\mathrm{O}$ detalhamento dos valores dos investimentos e dos custos de manutenção das embarcações de pesca encontra-se na Tabela 1.

\section{OS CUSTOS DE AQUISIÇÃO DE APETRECHOS}

Os barcos da frota apresentaram oito apetrechos na composição total dos seus equipamentos de pesca e o maior investimento deu-se para a aquisição da redinha, o apetrecho que concentrou aproximadamente $71,5 \%$ dos gastos. $\mathrm{O}$ segundo apetrecho em valor de aquisição foi o arrastão (Tabela 2). Em barcos que se utilizam somente de malhadeiras $(n=2)$, o custo de aquisição foi maior para as malhadeiras e para os apetrechos de fisga como a grozeira e o espinhel. Um detalhamento da forma de utilização, espécies-alvo e dos nomes similares dos apetrechos que ocorrem em toda a região amazônica, pode ser encontrado em Petrere Jr. (1978), Goulding (1979), Isaac \& Barthem (1995), Ruffino \& Isaac (2000) e Batista et al. (2004).

Os pescadores de canoas motorizadas (rabetas) apresentaram maiores investimentos na aquisição de redes de emalhar, como a malhadeira e o arrastão, que foram responsáveis por $40,9 \%$ e $42 \%$ do percentual dos investimentos (Tabela 2). Embora o número médio destes apetrechos por canoa motorizada seja diferente, o capital investido foi semelhante. O detalhamento dos custos dos apetrechos de pesca e o número médio dos mesmos por unidade de pesca (barco ou canoa) estão sumarizados na Tabela 2.

Em relação ao investimento na aquisição dos apetrechos de pesca das embarcaçôes, os proprietários foram os principais financiadores, sendo este percentual de aproximadamente $84,6 \%$, para os barcos, enquanto que os pescadores de canoas financiaram aproximadamente $92,9 \%$ da compra dos apetrechos.

Do percentual de pescadores de canoas financiados, $14,3 \%$ tiveram suas canoas e motores rabetas financiados pela Agência de Fomento do Estado do Amazonas - AFEAM, enquanto que 6,3\% obtiveram financiamento apenas para a aquisiçẫo das caixas isotérmicas e $9,1 \%$ somente para aquisição de apetrechos, mais

Tabela 1 - Investimento para a aquisição de equipamentos e máquinas pelos proprietários das embarcações de pesca.

\begin{tabular}{ccccc}
\hline \multirow{2}{*}{ Descrição } & \multicolumn{2}{c}{ Canoa motorizada } & \multicolumn{2}{c}{ Barco de pesca } \\
\cline { 2 - 5 } & Investimento (R\$) & $\%$ & Investimento (R\$) & $\%$ \\
\hline Apetrechos & $1.513,73$ & 35,9 & $10.054,38$ & 67,8 \\
$\begin{array}{c}\text { Canoas } \\
\text { auxiliares }\end{array}$ & $1.650,00$ & 39,2 & $3.390,00$ & 22,8 \\
Motor rabeta & $1.050,00$ & 24,9 & $1.390,00$ & 9,4 \\
\hline Total & $4.213,73$ & 100 & $14.834,38$ & 100 \\
\hline
\end{tabular}

especificamente redinha e malhadeiras. Apenas 15,4\% dos barcos apresentaram financiamento para aquisição dos apetrechos, mais especificamente arrastão e malhadeiras (Cardoso, 2005).

Recentemente, recursos advindos do Banco da AmazôniaBASA foram empregados para o financiamento da atividade pesqueira na região. Esses recursos foram destinados, principalmente, à aquisição de redinha, para pescadores de barcos, e malhadeiras, caixas de isopor, canoas e motores rabeta, para pescadores de canoas.

\section{CUSTOS DE MANUTENÇÃO DAS EMBARCAÇÕES}

Os custos de manutenção das embarcações da frota pesqueira local foram referentes à manutenção do motor de propulsão, calafeto (vedação dos interstícios existentes entre a madeira usada para confecção do barco ou da canoa), pintura e apetrechos constam na Tabela 3. A manutenção do motor e o calafeto foram os principais itens dos custos dos barcos de pesca e das canoas motorizadas. De maneira geral, os apetrechos apresentaram o menor percentual dos custos de manutenção das embarcações da frota pesqueira e correspondeu apenas aos gastos com a aquisição do material para o reparo.

A manutenção dos apetrechos dos barcos foi efetuada na própria embarcação, pela tripulação, envolvendo todos os pescadores $(5,1 \pm 2,3)$ que gastaram aproximadamente 7,7 $( \pm$ $4,1) \mathrm{h} / \mathrm{dia}$, no conserto dos apetrechos, principalmente da redinha. Os pescadores foram os principais financiadores dos custos de manutenção dos apetrechos de pesca.

Em geral, a manutenção do motor de propulsão (100\%), o calafeto $(57,1 \%)$ e a pintura $(83,3 \%)$ das embarcaçôes foi efetuado anualmente. $\mathrm{O}$ financiamento destes custos foi sempre

Tabela 2 - Quantidade e custos médios de aquisição dos apetrechos de pesca das embarcações da frota do município de Manicoré.

\begin{tabular}{|c|c|c|c|c|c|c|c|}
\hline \multirow{2}{*}{$\#$} & \multirow{2}{*}{ Apetrecho } & \multicolumn{3}{|c|}{ Canoa motorizada } & \multicolumn{3}{|c|}{ Barco de pesca } \\
\hline & & Unidades & $\mathrm{R} \$$ & $\%$ & Unidades & $\mathrm{R} \$$ & $\%$ \\
\hline 01 & Arco e flecha & 2,9 & 11,63 & 0,7 & - & - & - \\
\hline 02 & Arpão & 1,1 & 13,68 & 0,9 & - & - & - \\
\hline 03 & Arrastão & 1,3 & 635,45 & 42,0 & 2,0 & $1.200,00$ & 11,9 \\
\hline 04 & Caniço & 2,7 & 4,29 & 0,3 & - & - & - \\
\hline 05 & Currico & 1,7 & 16,00 & 1,1 & - & - & - \\
\hline 06 & Escolhedeira & - & - & - & 1,0 & 260,00 & 2,6 \\
\hline 07 & Espinhel & 5 & 66,00 & 4,4 & 6,0 & 75,00 & 0,7 \\
\hline 08 & Grozeira & 3,3 & 48,67 & 3,2 & 4,0 & 120,00 & 1,2 \\
\hline 09 & Malhadeira & 7,1 & 619,56 & 40,9 & 5,7 & 666,00 & 6,7 \\
\hline 10 & Redinha & 1,0 & $3.000,00$ & - & 1,3 & $7.193,38$ & 71,5 \\
\hline 11 & Tarrafa & 1,1 & 86,56 & 5,7 & 1,0 & 180,00 & 1,8 \\
\hline 12 & Tramalha & - & - & - & 3,0 & 360,00 & 3,6 \\
\hline 13 & Zagaia & 3,2 & 11,90 & 0,8 & - & - & - \\
\hline & Total & & $1.513,73^{\star}$ & 100 & & $10.054,38$ & 100 \\
\hline
\end{tabular}


Tabela 3 - Custos de manutenção das embarcações da frota pesqueira.

\begin{tabular}{ccccc}
\hline \multirow{2}{*}{$\begin{array}{c}\text { Item de } \\
\text { manutenção }\end{array}$} & \multicolumn{2}{c}{ Canoa motorizada } & \multicolumn{2}{c}{ Barco de pesca } \\
\cline { 2 - 5 } & $\mathbf{R} \$$ & $\%$ & $\mathbf{R} \$$ & $\%$ \\
\hline Motor & 49,89 & 30,3 & $1.348,57$ & 55,7 \\
Calafeto & 53,10 & 32,3 & 837,86 & 34,6 \\
Pintura & 43,77 & 26,6 & 184,67 & 7,6 \\
Apetrechos & 17,71 & 10,8 & 50,46 & 2,1 \\
\hline Total & 164,48 & 100 & $2.421,56$ & 100 \\
\hline
\end{tabular}

dividido entre os pescadores da tripulação e o dono do barco de pesca. No caso de aluguel de embarcação para a pesca, o proprietário arcou sozinho com as despesas recorrentes de problemas e manutenção do barco de pesca.

A manutenção dos apetrechos dos pescadores das canoas motorizadas foi efetuada pelos próprios pescadores em $88,9 \%$ dos casos. Quando os pescadores pagaram pela manutenção dos apetrechos, os mesmos arcaram pelos custos do conserto em $94,4 \%$ dos casos, sendo que nos 5,6\% dos casos restantes, os custos foram financiados pelo armador de pesca. Para a manutenção, os pescadores gastaram em média $3,0( \pm 0,9)$ dias consertando seus apetrechos e aproximadamente $7,3( \pm 3,1) \mathrm{h} /$ dia, utilizando a mão-de-obra que variou entre uma e quatro pessoas para o conserto (1,5 $\pm 0,7$ pescadores).

\section{CUSTOS DE COMERCIALIZAÇÃO}

A taxa de comercialização do pescado cobrada pela Colônia de Pescadores local para barcos e canoas a cada expedição de pesca é de $2,5 \%$, calculado sobre o peso do pescado comercializado, sendo este percentual (valor) convertido em Real (R\$). Para barcos de pesca não sediados no município e que desembarcam pescado no mercado local e para o pescado que é importado de outros municípios, o valor de comercialização cobrado é de $5 \%$. O valor é recolhido pelo funcionário da colônia, após a comercialização do pescado e recebimento do pagamento por parte dos compradores de pescado (marreteiros).

\section{CUSTOS DAS EXPEDIÇÕES DE PESCA}

O custo para a realização das expedições de pesca diz respeito a três itens principais: combustível (diesel, gasolina e óleo lubrificante), gelo e rancho, adicionados a estes, a taxa de comercialização cobrada pela colônia de pescadores.

O combustível foi o principal item componente dos custos a onerar as expedições de pesca das embarcaçôes da frota da regiāo. O segundo item, em termos de custo, foi o gelo. Os valores estipulados para os custos de armação das embarcaçôes encontram-se na Tabela 4.

De maneira geral, foram identificados seis agentes financiando os itens componentes das expedições das embarcaçōes de pesca da região estudada, entre os quais armadores de pesca, frigoríficos, pontão, comerciantes, marreteiros e pescadores. Dos agentes
Tabela 4 - Custos médios dos itens de armação das expedições de canoas motorizadas e barcos de pesca e taxa de comercialização.

\begin{tabular}{ccccccc}
\hline \multirow{2}{*}{ Itens } & \multicolumn{3}{c}{ Canoa motorizada } & \multicolumn{3}{c}{ Barco de pesca } \\
\cline { 2 - 7 } & Quantidade & Custo $(\mathrm{R} \$)^{*}$ & $\%$ & Quantidade & Custo $(\mathrm{R} \$)^{*}$ & $\%$ \\
\hline Propulsão & 10,6 & 27,54 & 35,2 & 182,6 & 353,36 & 54,2 \\
Gelo $(\mathrm{kg})$ & 110,6 & 25,03 & 32,0 & $2.858,3$ & 153,93 & 23,6 \\
\hline Rancho & - & 17,48 & 22,4 & - & 110,50 & 16,9 \\
Taxa & - & 8,10 & 10,4 & - & 34,20 & 5,3 \\
Total & \multicolumn{7}{c}{$-10,15$} & 100 & & 651,99 & 100 \\
\hline *Preços praticados em maio de 2004.
\end{tabular}

identificados, três financiaram as expediçōes das canoas durante o período: armadores de pesca, frigoríficos e pescadores, destes, o principal agente financiador foram os pescadores $(86,0 \%)$, sendo de importância secundária o financiamento efetuado pelos marreteiros $(9,3 \%)$ e armadores $(4,7 \%)$ no financiamento das expediçôes (Fig. 3).

As expediçōes de pesca dos barcos foram financiadas por cinco agentes: comerciantes, frigorífico, pontão, marreteiros e pescadores, sendo os principais agentes financiadores os pescadores $(40,9 \%)$ e o frigorífico $(27,3 \%)$ (Fig. 3). Não foi identificada a participação dos armadores de pesca no financiamento das expedições dos barcos.

O gelo foi o principal item financiado nas expedições das canoas motorizadas, tendo a participação dos três agentes (Fig. 4), porém esse financiamento não ultrapassou $13 \%$ das expediçōes. Nos barcos de pesca, o gelo foi o único item que teve maior financiamento ( $50 \%$ das expediçōes), sendo financiado pelo frigorífico. O combustível foi o item que teve mais fontes de financiamento para os barcos (Fig. 5).

O custo das expediçōes dos barcos de pesca e das canoas motorizadas foi de aproximadamente $47,7 \%$ e $24,1 \%$, respectivamente, da renda bruta gerada pela comercialização do pescado, sendo que este percentual aumentou para $50,2 \%$ para os barcos e $26 \%$ para canoas, quando foi adicionada ao custo da

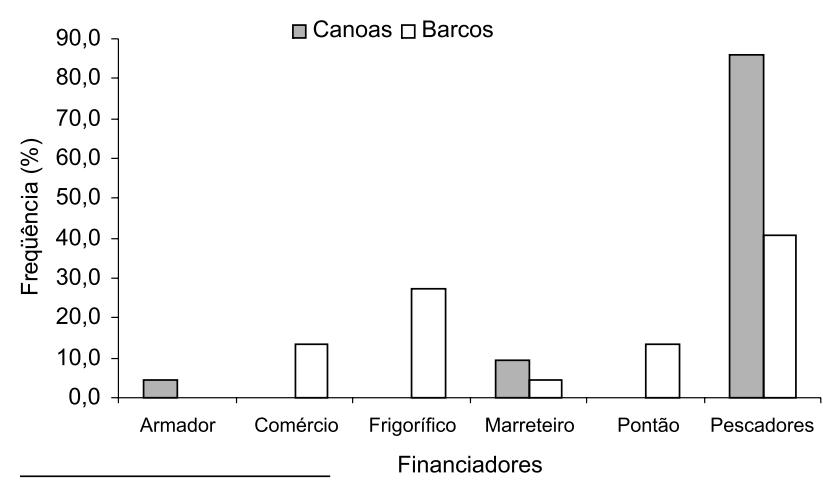

Figura 3 - Agentes financiadores das expedições de pesca das embarcações do município de Manicoré. 


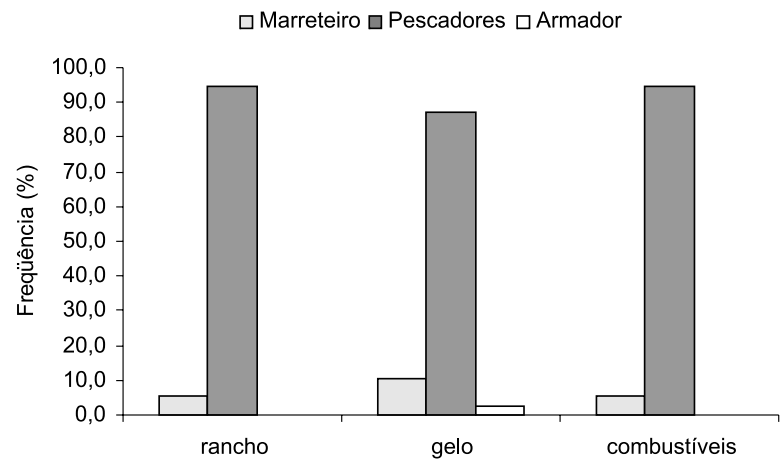

Figura 4 - Agentes financiadores dos custos das expedições das canoas motorizadas.

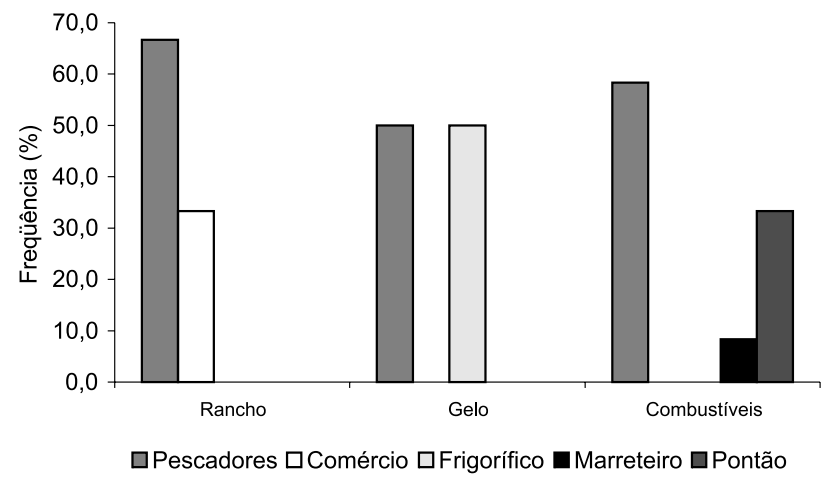

Figura 5 - Agentes financiadores dos custos de armação das expedições dos barcos de pesca.

expedição, a taxa de comercialização do pescado cobrada pela colônia de pescadores.

\section{A RENDA DA ATIVIDADE PESQUEIRA}

A divisão dos custos de armação das expedições dos barcos de pesca ocorreu de maneira igualitária entre os pescadores da tripulação. A comercialização do pescado e distribuição da renda ocorreu da seguinte maneira: o encarregado negociou o pescado e recebeu o valor da venda, em seguida foram descontados os valores relativos aos custos de armação e da taxa de comercialização sendo realizada aí a divisão das partes. $\mathrm{O}$ armador recebeu em média 2,2 $( \pm 0,9)$ partes, enquanto o encarregado recebeu 1,9 $( \pm 0,7)$ parte, o restante da tripulação recebeu uma parte por expedição de pesca efetuada.

A divisão da renda entre os pescadores das canoas motorizadas foi efetuada de maneira igual entre os participantes das viagens.

A renda bruta das embarcações, bem como a remuneração mensal dos pescadores, são mostrados nas Tabelas 5 e 6 . Para os pescadores dos barcos de pesca, que efetuaram em média 2,0 ( \pm $0,8)$ expedições mensais, a remuneração do armador e do encarregado foi de 1,3 e 1,1 salário mínimo respectivamente, enquanto que a remuneração dos pescadores não ultrapassou 0,6 salário mínimo. Pescadores de canoas motorizadas, que efetuaram em média $4,0( \pm 3,0)$ expedições mensais, obtiveram remuneraçāo de dois salários mínimos.

\section{DISCUSSÃO}

Apesar da dimensão continental da região amazônica, algumas características físicas e operacionais da frota pesqueira existente são similares, principalmente pela aparente não diferenciação entre os estoques pesqueiros explotados (Almeida et al., 2003). Isso faz com que essas características sejam mais facilmente comparáveis e passíveis de regulamentação de caráter mais amplo. Uma característica similar em todas as microrregióes que formam a Amazônia, são os agentes de produção (pescadores) que compõem a frota (Parente, 1996). A exceção éa inexistência de alguns agentes de produção específicos que formam a frota de outros locais como os barcos compradores e barcos mistos.

Por ser uma das principais atividades do setor primário em geração de emprego e renda que não carece de mão-de-obra formalmente especializada para a sua execução (exceção da pesca industrial existente no estuário amazônico), a pesca absorve uma quantidade considerável de pessoas trabalhando direta e indiretamente na atividade (Fisher et al., 1992; Almeida et al., 2001). Devido a isso, a entrada de novas embarcaçōes na atividade é facilitada, somada ao fato do governo não exercer um controle efetivo sobre o número real de barcos e de canoas motorizadas existentes. Um outro fator que favorece a entrada de novos pescadores é o caráter de livre acesso ao recurso existente e a facilidade encontrada pelos indivíduos para a captura do pescado, principalmente na época de seca, quando os cardumes de peixes são mais abundantes e os peixes encontram-se mais vulneráveis, devido à redução da lâmina de água dos ambientes, não sendo necessária grande experiência na atividade, nem apetrechos específicos para a captura.

Tabela 5 - Renda média das expedições das embarcações de pesca.

\begin{tabular}{cccc}
\hline Embarcação & Renda Bruta(R\$) & Custo da Expedição (R\$) & $\begin{array}{c}\text { Renda Líquida } \\
\text { (R\$)* }\end{array}$ \\
\hline Barco & $1.368,00$ & 651,99 & 681,81 \\
Canoa & 324,10 & 78,15 & 237,85 \\
\hline
\end{tabular}

* Renda bruta subtraída dos custos expedição.

Tabela 6 - Remuneração dos armadores e da tripulação das embarcações da frota pesqueira.

\begin{tabular}{ccccccccc}
\hline & \multicolumn{3}{c}{ Canoa motorizada } & \multicolumn{4}{c}{ Barco de pesca } \\
\cline { 2 - 9 } & \multicolumn{2}{c}{ Expedição } & \multicolumn{2}{c}{ Mensal } & \multicolumn{2}{c}{ Expedição } & \multicolumn{2}{c}{ Mensal } \\
\cline { 2 - 10 } & R\$ & SM1 & R\$ & SM & R\$ & SM & R\$ & SM \\
\hline Armador & 118,92 & 0,5 & 475,69 & 2,0 & 150,68 & 0,6 & 301,36 & 1,3 \\
Encarregado & - & - & - & - & 131,59 & 0,5 & 263,18 & 1,1 \\
Pescador & 118,92 & 0,5 & 475,69 & 2,0 & 68,18 & 0,3 & 136,36 & 0,6 \\
\hline
\end{tabular}

1- SM: Salário mínimo em maio de 2004 de $\mathrm{R} \$ 264,00$; 
Essa facilidade de entrada de barcos de pesca e de canoas motorizadas na atividade é atualmente favorecida pelo oferecimento de financiamento oficial, níveis federal e estadual, para a aquisição de novos barcos, motor de propulsão e apetrechos. Porém, como demonstrou o estudo, a maioria dos proprietários de embarcações de pesca no município de Manicoré não necessitou de financiamento externo para a aquisição dos apetrechos e das canoas. Esta independência pode ser um entrave ao uso de instrumentos econômicos em planos de ordenamento da pesca na região, como ocorreu na limitação do número máximo de embarcações da pesca industrial da piramutaba (Brachyplatystoma rousseauxii) no estuário do rio Amazonas, por intermédio da suspensão de incentivos (Isaac et al., 1993).

Comparando os investimentos para a aquisição dos bens entre os pescadores de canoas motorizadas e de barcos de pesca, tornouse evidente a diferença entre os valores empregados pelos proprietários das embarcaçôes. Os investimentos para aquisição dos apetrechos de pesca e canoas auxiliares dos barcos apresentaram valores sete e duas vezes maiores que as canoas, respectivamente. Uma explicação para este fato se dá na diferenciação dos apetrechos que são adquiridos pelas embarcaçôes, que são mais onerosos para os barcos (redinha) do que para as canoas (malhadeira) e das canoas auxiliares, maiores e exigem um maior esforço para confecção para os barcos de pesca, tornando-se evidente que os pescadores de canoas motorizadas têm maior facilidade em termos de investimento inicial, para adentrar na atividade pesqueira, frente aos pescadores dos barcos de pesca.

Diferente do que ocorre na região da Amazônia Central, onde os custos das expedições de pesca são financiados principalmente pelos armadores de pesca, despachantes e por outros agentes (Parente, 1996; Cardoso et al., 2004), na região do Médio rio Madeira esses custos foram na sua maioria, financiados pelos pescadores das embarcaçōes, semelhante ao que ocorre em embarcaçōes de pequeno porte na região do Baixo Amazonas (Almeida et al., 2000), onde os pescadores, além de financiarem as expediçôes, são os donos dos apetrechos. Essa independência parcial dos pescadores que financiam suas expediçōes pode ser benéfica, pois os mesmos não ficam atrelados a nenhum agente de comercialização, como ocorre em outras regiōes (Falabella, 1994; Parente, 1996; Faria Júnior, 2002; Cardoso et al., 2004) o que lhes permite negociar com mais liberdade o preço de venda do pescado, possibilitando um retorno mais rápido do capital investido.

Uma provável explicação para o maior financiamento dos custos pelos pescadores, pode ser a inexistência do despachante nesta região, visto que este é o principal agente financiador das expediçōes na Amazônica Central (Falabella, 1994; Parente, 1996; Faria Júnior, 2002; Cardoso et al., 2004). Este agente é substituído, em pequena proporção nesta região, pelo marreteiro, que eventualmente financia algum item da expedição de pesca para algumas embarcaçōes.

A distribuição dos agentes por item dos custos de expedição segue a lógica comum em todas as pescarias, onde o rancho é financiado pelos comerciantes (supermercados e mercearias), enquanto que frigorífico financia o gelo e o pontão (posto de combustível flutuante) financia os combustíveis. Dos três itens componentes dos custos por expedição, apenas o gelo foi financiado em igualdade por pescadores e frigorífico. As relações de confiança (compadrio e os laços familiares), mais comuns em pequenos centros urbanos, poderiam facilitar a aquisição de financiamento dos itens para a armação das embarcaçōes, porém isso não foi notado, devido ao alto índice de financiamento próprio dos pescadores.

Uma das estratégias utilizadas pelos pescadores dos barcos desta região, para diminuir os custos de uma expedição de pesca e aumentar a rentabilidade, é o envio do pescado que é capturado e que não completa a carga total do barco, para a comercialização. O transporte do pescado se dá por outros barcos de pesca ou por intermédio dos barcos de passageiros. O pescado pode vir acompanhado ou não por um pescador do barco, dependendo da necessidade de se retornar ao local onde o barco está ancorado, com algum item que esteja faltando para a tripulação. $\mathrm{O}$ custo de envio deste pescado é somado ao custo total da expedição. A economia se dá basicamente no item combustível (propulsão), que é conservado com o não deslocamento do barco até o porto de desembarque, visto que este foi o principal item em termos de custo da expedição. Enquanto na região da Amazônia Central, a despesa com combustível alcançou entre 30 a $45 \%$ dos custos operacionais com a expedição de pesca (Cardoso et al., 2004), a frota local apresentou percentual acima dos custos destes barcos. Esse aumento pode ser consequiência da não participação do gelo nos custos de muitas expedições de pesca ou pelo deslocamento de barcos para pesqueiros afastados da sede do município (Cardoso, 2005).

O gelo, apesar de ser o segundo item a onerar os custos das embarcaçōes, tem seu efeito anulado na maioria das expedições dos barcos que têm como destino, os locais de pesca no rio Manicoré, pois estes não utilizam gelo nessas expediçōes. Isso se deve basicamente a pouca distância destes pesqueiros para o local de desembarque na sede do município (Cardoso, 2005), não sendo necessária a utilização do gelo para conservação do pescado. Essa economia não ocorre, porém, para as pescarias das canoas motorizadas, devido, principalmente, à quantidade de pescado que é capturado por período de pesca, que torna economicamente inviável o retorno desses pescadores para a comercialização do pescado, e, portanto necessitam de gelo para a conservação do pescado (Cardoso, 2005).

$\mathrm{Na}$ região da Amazônia Central, os pescadores são remunerados de acordo com a função que exercem na embarcação 
de pesca pelo sistema de cotas-parte (Falabella, 1994; Parente, 1996; Cardoso et al., 2004), podendo ganhar cotas a mais de acordo com a efetividade de participação na expedição de pesca, ou pelo acúmulo de funções (Faria Júnior, 2002). Porém, na região estudada, constatou-se que, como os pescadores não possuem função específica definida, a remuneração dos mesmos é efetuada de maneira igual, sendo diferenciada apenas a remuneração do armador e do encarregado do barco. Cardoso $e t$ al. (2004), em levantamento efetuado na região da Amazônia Central, levando em consideração o tamanho do barco de pesca, encontraram valores de remuneração dos pescadores que variou entre 0,6 a 2,2 salários mínimos. Em comparação com esses pescadores, os sediados nesta região tiveram remuneração inferior.

Os valores da renda dos pescadores apresentados neste trabalho devem ser observados com cautela. Embora a coleta de dados tenha sido efetuada em período anual, os mesmos derivam de apenas uma expedição de pesca de cada pescador amostrado. Devido às características específicas da região amazônica, os valores da renda podem variar de acordo com o ciclo hidrológico, que interfere positiva ou negativamente nas capturas e com as estratégias adotadas pelos encarregados e pescadores de barcos de pesca, que podem, por exemplo, levar o pescado capturado para ser comercializado em outros locais devido a melhores valores de comercialização.

Um outro fator que não foi incluído nos cálculos da renda das expedições foram os custos com a manutenção, que acontecem a cada expedição (no caso dos apetrechos) e anualmente, como os reparos no motor de propulsão, calafeto e pintura. Quando esses custos forem somados aos custos operacionais, poderão tornar ainda menor a renda para os pescadores das embarcaçóes.

Com os fatos evidenciados aqui, torna-se imperativo que estudos de longo prazo, que visem elucidar as características sociais e econômicas da atividade pesqueira nas regiōes periféricas aos grandes centros consumidores de pescado, sejam efetuados, para se ter uma melhor visão da renda da atividade.

\section{CONCLUSÕES}

A análise efetuada dos dados coletados durante o estudo, permitiu concluir que:

a) Para a inserção na atividade pesqueira da região não há a necessidade de financiamento externo, pois os pescadores foram os principais financiadores, tanto dos apetrechos quanto dos custos das expediçóes de pesca para o período estudado;

b) Os combustíveis foram os principais itens dos custos com as expedições de pesca para os barcos e tiveram peso igual ao gelo para as expediçôes dos pescadores de canoas motorizadas;

c) De maneira geral, os pescadores das canoas motorizadas tiveram maior rendimento econômico por viagem de pesca em comparação com os dos barcos.

\section{AGRADECIMENTOS}

Os autores agradecem ao CNPq pelo financiamento do projeto (Edital Universal 2002, Processo $\mathrm{N}^{\circ} 472581 / 2003-1$ ) e pela concessão da bolsa de mestrado, ao MSc. Charles Hanry Faria Júnior. Aos revisores, pelas sugestōes e críticas ao manuscrito, ao apoio da Colônia de Pescadores Z-20, aos colegas do Laboratório de Ecologia da Pesca da Universidade Federal do Amazonas e a todos os pescadores do município de Manicoré, AM, que forneceram as informaçōes, sem as quais este trabalho não teria sido realizado.

\section{BIBLIOGRAFIA CITADA}

Almeida, O.T.; McGrath, D.G.; Ruffino, M.L. 2001. The commercial fisheries of the lower Amazon: an economic analysis. Fisheries Management and Ecology, 8: 253-269.

Almeida, O.T.; Lorenzen, K.; McGrath, D.G. 2003. Commercial fishing in the Brazilian Amazon: regional differentiation in fleet characteristics and efficiency. Fisheries Management and Ecology, 10: 109-115.

Almeida, O.T.; McGrath, D.G.; Arima, E.; Ruffino, M.L. 2000. Production analysis of commercial fishing in the Lower Amazon. International Association for the Study of Common Property-IASCP. Bloomington, IN, USA. Disponível em: http:// www.indiana.edu/ - iascp2000.htm

Barthem, R.B. 1999. A pesca comercial no Médio Solimões e sua interação com a reserva Mamirauá. In: Queiroz, H.L.; Crampton, W.G.R. (Eds). Estratégias para manejo de recursos pesqueiros em Mamirauá. Sociedade Civil Mamirauá - CNPq, Brasília. p. 72-107.

Batista, V.S. 1998. Distribuição, dinâmica da frota e dos recursos pesqueiros da Amazônia Central. Tese de Doutorado. Instituto Nacional de Pesquisas da Amazônia/Fundação Universidade Federal do Amazonas, Manaus, Amazonas. 282pp.

Batista, V.S.; Petrere Jr., M. 2003. Characterization of the commercial fish production landed at Manaus. Acta Amazonica, 33(2): 291302.

Batista, V.S.; Isaac, V.J.; Viana, J.P. 2004. Exploração e manejo dos recursos pesqueiros da Amazônia. In: Ruffino, M.L. (Coord). $A$ pesca e os recursos pesqueiros na Amazônia brasileira. IBAMA/ PROVÁRZEA, Manaus. p. 63-151.

Beiguelman, B. 2002. Curso prático de bioestatística. $5^{\mathrm{a}}$ edição. FUNPEC Editora, Ribeirão Preto. 273pp.

Berkes, F.; Mahon, R.; McConney, P.; Pollnac, R.; Pomeroy, R. 2001. Managing small-scale fisheries: Alternative directions and methods. International Development Center Research - IDCR, Canada. 320pp.

Cardoso, R.S. 2005. A pesca comercial no município de Manicoré (rio Madeira), Amazonas, Brasil. Dissertação de Mestrado, Instituto Nacional de Pesquisas da Amazônia/ Universidade Federal do Amazonas, Manaus, Amazonas. 149pp.

Cardoso, R.S.; Batista, V.S.; Faria Júnior, C.H.; Martins, W.R. 2004. Aspectos econômicos e operacionais das viagens da frota pesqueira de Manaus, Amazônia Central. Acta Amazonica, 34(2): 301-307. 


\section{ACTA
AMAZONICA}

Falabella, P.G.R. 1994. A pesca no Amazonas: problemas e soluçôes. 2a edição. Manaus: Imprensa Oficial do Estado. 180pp.

Faria Júnior, C.H. 2002. Aspectos da composição dos fatores econômicos, capital imobilizado e repartição da renda, na pesca que abastece Manaus, Amazonas. Dissertação de Mestrado. Instituto Nacional de Pesquisas da Amazônia/Fundação Universidade Federal do Amazonas, Manaus. 92pp.

Fisher, C.F.A.; Chagas, A.L.G.A.; Dornelles, L.D.C. 1992. Pesca de águas interiores. Coleção Meio Ambiente, Série Estudos Pesca 2. IBAMA, Brasília. 32pp.

Goulding, M. 1979. A ecologia da pesca no rio Madeira. CNPq/INPA, Manaus, 172pp.

IPT. 1979. Avaliação da atual frota pesqueira amazonense e proposição de novas concepçōes. Relatório Técnico, IPT, São Paulo, 219pp.

Isaac, V.J.; Rocha, V.L.C.; Mota, S.Q. 1993. Consideraçôes sobre a legislação da "piracema" e outras restrições da pesca da região do Médio Amazonas. In: Furtado, L.G.; Mello, A.F.; Leitão, W. (Eds.). Povos das águas: realidade e perspectiva na Amazônia. MPEG/UFPA, Belém. p. 187-211.
Isaac, V.J.; Barthem, R.B. 1995. Os recursos pesqueiros da Amazônia brasileira. Bol. Mus. Par. Emílio Goeldi, Série Antrop., 11(2): 295-339.

Parente, V.M. 1996. A economia da pesca em Manaus: organização da produção e da comercialização. Dissertação de Mestrado, Universidade Federal Rural do Rio de Janeiro, Rio de Janeiro. 178pp.

Petrere Jr., M. 1978. Pesca e esforço de pesca no Estado do Amazonas. II. Locais e aparelhos de captura e estatística de desembarque. Acta Amazonica, 8(Suplemento 2): 1-54.

Petrere Jr., M. 2004. Setor pesqueiro: Análise da situação atual e tendências do desenvolvimento da indústria da pesca. Relatório Técnico, IBAMA/PROVÁRZEA, Manaus, 97pp.

Ruffino, M.L.; Isaac, V.J. 2000. A pesca artesanal do Médio Amazonas. In: Recursos pesqueiros do Médio Amazonas: biologia e estatística pesqueira. Coleção Meio Ambiente, Série Estudos Pesca, 22. IBAMA, Brasília. p. 317-348.

Rcebido em 11/05/2005

Aceito em 27/09/2006 
